\title{
THE ANNUAL MEETING
}

ThE second Ordinary General Meeting of the Institute was held at The Royal Society of Arts, 18, John Street, Adelphi, London, W.C., on Monday, July 4. 1927.

The Right Hon. The Earl of Balfour, K.G., O.M., F.R.S., presided.

Professor L. T. HoBhouse, M.A., D.Litt., LL.D. (Chairman of the Council), in proposing that the Annual Report and Statement of Accounts be adopted, said : Lord Balfour, Ladies and Gentlemen,- these resolutions are necessitated by the general business of the Institute. They are, in the first place, for the adoption of the Annual Report and Statement of Accounts, and each resolution is open to discussion. The second resolution is for the reelection of the retiring members of the Council ; the third resolution is that certain members of the Council, who have lapsed from membership owing to the fact that they have lectured to the Society and have therefore under the Articles ceased ipso facto to be members of the Councul, should be re-elected ; the fourth resolution is for the election of the Prime Minister of New Zealand as a member of the Council; then there is also a resolution increasing the number of members of the Council from IIo to II5, partly to accommodate some of these distinguished gentlemen. Finally there is a vote of thanks to Messrs. Deloitte, Plender, Griffiths \& Co. for their services as honorary auditors and a proposal for their re-election for the ensuing year. I shall not say anything here in detail with regard to those separate motions, but I should like to take the opportunity, in moving them, of saying a word or two about the problems before the Institute.

I think, looking back over the two years of its existence, that it will be admitted by a large number of its members that it has given a very good account of itself. It has had a difficult work to perform, the extraordinarily difficult task of conciliating the genuine scientific, thoughtful, thoroughgoing study of philosophy with an appeal to the public which cannot be specifically and professionally concerned in philosophical studies. There is in that an inherent difficulty, and I think that we have been fortunate in the Editor of our Journal and Director of Studies, who has, I think, known well how to adapt himself to this extremely difficult situation. The Joumal in particular has done well and has become known outside the immediate circles of the Institute, which is always a very good sign of progress.

Still, there remains the task of extending our boundaries, if we can, and increasing our membership. We need that partly for financial reasons, but also largely for the direct objects for which we exist, namely the extension of the interest in philosophy. Everyone who joins us is a potential recruit to the realms of light-shall we say ?-and everyone who is a member can do something to bring other recruits in. We also need financial help because we want very greatly a home for the Institute. We cannot go at full power until we have a library and a permanent place for the gatherings of students-a place where the Director of Studies can always be found-and to find such a building is the ambition which those of us working here for the Institute naturally have before us at all times. The possibility of getting donations from those funds which cater for educational objects is contingent and shadowy ; it depends upon chances and possibilities which we cannot com- 


\section{JOURNAL OF PHILOSOPHICAL STUDIES}

mand, while pious donations are an incalculable entity. You do not know where a donor will pass along or whether you will be there when he does. With regard to the more regular sources of funds to which we ourselves contribute as members, it is also possible for us to add to them by evangelization among the people who are likely to form possible recruits, and it is that to which I would stir the energies, if I may say so, of all the members.

They will always have to combat a great deal of prejudice in the matter of philosophy. The utilities of science are very obvious as they get certain material results ; the utilities of philosophy require a different kind of perception to understand and appreciate them, and of course there is a great deal of prejudice of this kind which philosophy has to contend with. It is said that it is essentially unprogressive, and people point to the smallness of its achievements as contrasted with the very striking and magnificent results which science has attained. It is said that while we have evidently passed the ancients, the men of the Middle Ages and the men of the early modern period in all the essentials of civilization and in the application of science to human uses ; in regard to philosophy it is doubtful whether we have got very much further than the great men of old and whether we have produced any men of genius equal in penetration to the men of classical antiquity. That is against philosophy ; there is a certain sense of hopelessness with which many turn from philosophy, urging that the philosopher is hammering away at the old questions with the same hammer, trying to drive in the same nails, but that they only get a little blunter by the experience of the hammer in the hands of successive generations.

In consequence I think that people very often tend to turn away from a subject which appears to be unprofitable; yet others believe that philosophy is not so much without progress as appears, and that still less is it without hope in the future and present utility in our lives-a less palpable but perhaps more real utility than that which comes from the sciences. The reason of that, I think, is this. Philosophy deals with one problem from first to last. I do not know how you could formulate it. It is the problem, I suppose, of man in his life and his position in the universe. That problem has not changed ; it has gone on all through the generations. Man has not materially changed, and it is an inexhaustible problem. It is not one which you can solve and then pass on to something else. It is one to which every other problem contributes some new question, and in solving one difficulty you make others, and that is markedly the case in modern civilization as compared with the simpler life of antiquity. While philosophy solves some of the problems of antiquity and has made the world safer for civilized man, yet in doing so it has brought up tremendous problems of the incalculable stress and strain of society.

Therefore it must be admitted in a sense that we do not progress as science does by solving problems and passing on to others, but there is always the one great central problem, that of life as a whole and the universe as a whole. There is always this one great problem, and so we are bound to be always going round the same point and returning to the same subject; but it does not follow that we make no advance and that our work is utterly fruitless. When we try to see things as a whole, it is true that we may perhaps, at first glance and through great difficulties, get-in a physical and literal sense-a certain view of things as a whole, and see a forest or mountains or a town or buildings, and may get a certain coup d'oil from a distance. In that way you see the thing as a whole, in a way which you perhaps lose when you come to closer quarters, when you cannot see the wood for trees, and you cannot see the town because you are inside it. 


\section{THE AN NUAL MEETING}

Yet it is all the time true that you are learning more and more, and something is being learned all the time. Something like that has been happening in the history of philosophy and its relation to the sciences. The ancient philosopher saw more of life as a whole than we do. It was easier for him, but after a time these early philosophers discovered that it was not quite so simple a question but that it contained a number of distinct though co-related questions. Succeeding generations also found that and began to describe specific sciences, but they also maintained, as Plato had, that the philosopher must begin by a study of those specific sciences, seeing them in relation to each other. It is only the person who can see them either together or in relation who can become converted to the dialectical method which was for Plato the task of philosophy. It was seen that one must break up knowledge and yet reunite it, and that was the ultimate problem of philosophy.

That process of revision has gone on at a very greatly accelerated pace by the modern world, and it came to be realized that a division might have to be set up again, a deeper division than was in the minds of the ancients; and so we came to the Descartes's division between mind and matter. That division was at once most fruitful, and was also, perhaps, the most dangerous that ever was made in the history of human thought. It was the most fruitful because it turned out empirically to be possible to treat large tracts of the things which you were investigating in terms of extension or other terms which were understood in the seventeenth century by Newton and others, which now, it seems to be thought by advanced scientific thinkers, may be resolved into some development of the Cartesian extension. So Descartes seems to have been in advance of his time if the present movement is to make good. At any rate, there was that tremendous division, bridgeable only by a miracle; this gulf between extension on the one side and the world of thought and mind on the other; and out of that division there came incidentally the means of science's noblest success-that of physical science by resolving things into terms of geometry, number and magnitude. By that physical science achieved its most brilliant success.

The other side, the investigation of the mind, on the contrary, gradually fell out of the scientific world, and whereas in the seventeenth century people would certainly use the word "philosopher" of Newton, it gradually became the idea that the principal study of Philosophy was the mind, and that it did not make the same progress as did the investigation into physical nature. Therefore, the Cartesian division had a tremendous practical success, and yet I think that the end of this great success has been up to date that those who have succeeded most in it have begun to doubt the validity of the whole thing and to ask whether the principles upon which they have gone are really adequately representative. They may be in the sense that you can conduct experiments and make calculations on that basis, which will generally come out right in certain regions of the world. But in this method certain factors in the total situation have to be left out of account or ignored.

On the other hand, the light which you want, the illumination which you hope for from your investigations as to the real nature of things, seems not brighter but perhaps rather dimmer in some respects with the progress of knowledge. It does not seem that your final light is coming in that way, and this seems to have been realized more by philosophers in our time than ever before. Out of the present situation there must come from the side of mind and from the physical side a certain movement towards reunion, We have got to think of the world as a whole in which there is mind as well as matter ; in which one side is as great as the other, and in which accuracy and calculation is not as such a definite measure of truth in the understanding of reality. 


\section{JOURNA OF PHILOSOPHICAL STUDIES}

That is the situation which we have to keep before ourselves. We must endeavour to get the best general view of knowledge and experience that is possible. It is always worth while trying to bring together the new lights that come, trying to work into relation the many exceedingly divergent branches in which knowledge has already been pursued with great success, and trying to see some sort of intelligible pattern, some sort of fruitful result of the whole thing. I think that it is only in that way that the immensely advanced knowledge of the world is going to be made of real use for the generations that are coming.

We have a great deal of education and an immense amount of specialization. We have, perhaps, too great demands made upon the young, for they have to know something of all these new subjects. I do not know that they get very much better educated than was the case in my generation, because their knowledge is not brought together sufficiently to make any coherent, intelligible and working whole in their minds. I think it is the philosopher's task to try to make the best of the knowledge that is coming forward in his own generation. It is difficult. If you try writing a book in which two subjects are introduced, you will find that those subjects will change as you are writing the book. I have had that experience. However, it is worth the attempt, and it is in the hope that this attempt will go forward and succeed; and in the belief that whatever the future may be, the task of making knowledge coherent for our own generation (and thereby helping to make our lives healthy, sane and reasonable), is worth doing, that the study of philosophy can be of exceptional value. That is the task that the Institute is called upon to participate in, and I therefore hope that you will do all you can to support its influence and extend its membership (Applause.)

The resolution for the adoption of the Annual Report and Statement of Accounts for the year ended March 3I, 1927, was then put to the meeting and carried with one dissentient.

The Right Hon. the Earl of Balfour, K.G., O.M., F.R.S. (the President) : Ladies and Gentlemen,--Professor Hobhouse has given, I think, a very admirable survey ranging over the general aspects of philosophy and of science, their present position, their present duties and their future prospects. I would venture to approach the same theme from a somewhat different point of view. To me it has always seemed-and I should imagine that on reflection it will seem to all of you whom I am addressing - that the business of philosophy is only one which comes before the human being interested in such matters at a certain stage of his intellectual development. He is already furnished, by the time he becomes a philosopher or a would-be philosopher, with a creed involving beliefs about the world in which we live, about the men and women with whom we come into contact, about science and about religion. He comes, in other words, furnished with a large body of beliefs, and if philosophy appeals to him-at all events, if it appeals to him in the same way as it appeals to me-the problem that he has to deal with is an individual and personal problem, which comes to this in each case : "How am I, A, B, C, or $D$, whoever I may be, to deal with this mass of beliefs which regulate my actions and which, in other shapes, perhaps, regulate the actions of my fellow creatures? How am $I$ to deal with my own beliefs in a manner which shall satisfy my own reason; how am I to make, as far as it can be made, a coherent creed out of the vast mass of beliefs, scientific and other, with which I find myself furnished, with the position and the education which I occupy and have received in the social world-the world of human society ?"

That, you observe, is a personal question, in the sense, I mean, that it is a 


\section{THE ANNUAL MEETING}

question which each person raises for himself and, with the best assistance he can obtain, attempts to deal with. In these days, perhaps, there will be a very large number of educated persons to whom a fairly simple answer to that problem presents itself. They will say, "All our knowledge is derived from experience." It is science which deals with experience, and more particularly and obviously with our experience of the material universe. Cannot we leave it to science to the best of its ability to carry out that work of satisfying reflective reason, which I have ventured to describe as being the main business of philosophy for each individual philosopher?

That is a very plausible position. As Professor Hobhouse has reminded you, the growth of science has been prodigious and most fruitful. It is moving, so far as I am able to judge, at this moment at which I am speaking to you, with a greater rapidity of evolution than at any previous moment in the history of mankind, and it might well seem that to science, to this great and successfully organized effort to understand the world in which we live, might be left the task of seeing that that organized science satisfies our reflective reason.

That is not only a possible way of looking at things; my conviction is that it is a very widespread way of looking at things, and that, at all events in the last century, there was a great body of the very ablest thinkers of the time who were under the impression that science had really found, not the key to all knowledge- of course not-but had at all events discovered the broad outlines on which we could form a not inaccurate, though doubtless very inadequate, picture of the world in which we live. Professor Hobhouse has reminded you that probably that attitude of self-confidence is far less widespread now among the greatest scientific thinkers than in the days which I well remember-the days of the last thirty years of the nineteenth century. Science itself has raised so many questions which it is unable to answer that no great man of science is now given, so far as I am able to judge, to being over-dogmatic.

That, however, is not the point on which I wish you to concentrate your attention. My point is a different one. The world of science takes as its province the explanation of the causes of all phenomena, whatever those phenomena may be. Based upon experience-and experience is experience of phenomena-science takes, if I may repeat the phrase, as its province the explanation of all that is and all that we can experience. If it does that, we have to remember that among the things which by the very terms of the statement I have just made, it is obliged to consider and obliged to explain, are those very scientific beliefs which constitute the body of our scientific knowledge. Those are phenomena like other phenomena; they are facts in a world of facts. "They come into what has been called the "causal web" as the effects of preceding causes and as the causes of succeeding effects. They are strictly, therefore, a subject with which science, as science, is bound to deal and with which science does deal.

That means that science explains the manner in which scientific beliefs or our experiences-our experiences of the world in which we live-come about. Modern science has told us a great deal of the manner in which those experiences come about, which was quite unknown, or barely known in outline, to our ancestors. How do our experiences come into being according to science? What is the cause of their being there? What is the cause of the experiences which every man and woman $I$ am addressing at this moment has lived through ever since they came as intelligent beings into the world in which we live? Science tells you ; there is no taste of philosophy in the answer; but, if you analyse the answer of science to that question, which deals with a 


\section{JOURNAL OF PHILOSOPHICAL STUDIES}

scientific problem, the answer can be given in a very few words. All that we know about the world in which we live is obtained by a series of messages sent from that world to each individual observer. At every moment of our lives, we are, as it were, receiving measages from all parts of the universe, just as in your own homes you obtain by post-by the same post perhaps-a letter from Australia and a letter from the next street, which reach you at the same time, though the facts of which they give you news happened at very different times. That simple illustration exactly tells you what is happening on a much more enormous scale when we observe the material world in which we live.

You look out, for example, on a fine night, and the messages which you get, at, say, half-past ten reach you all at the same moment, but they originated at their sources at moments which may differ by millions of years. What you see, for instance, in some nebula beyond the Milky Way happened no doubt long before this earth on which we live became a region in which organized life, as we know it, could have its being. The system of messages is not merely from the farthest limits of visible space, but it embraces and touches everything both great and small ; it extends throughout space which is difficult to describe in figures owing to its magnitude. In referring to this system of messages, I deliberately use a very unphilosophical and unscientific term, but it is accurately a system of messages, because from all space, through what we quite inaccurately call " empty" space, it reaches the living organism. In the organism, again by a system of messages, the electrical messages which have travelled through those illimitable distances are converted by a process (as yet wholly unrealized) in our spirit organism into experiences-individual mental experiences - and the organism which, according to science, performs this miracle again exists by virtue of an internal arrangement of messages between the different organisms, the different molecules, the different atoms, which make up our several organizations. Those are built up into all that we know and all that we believe. We know and believe because we have received those messages, by methods about which science is learning more and more every day, from the unlimited regions of the physical world which surrounds our bodies.

However much that way of putting it may be disapproved by the man of science, whether he be a physicist or a psychologist, I think it, however inadequately, not inaccurately represents what is actually going on at every moment of our waking lives. It is the way we come to know something about the world in which we live and the method by which the world we live in becomes part of our consciousness and forms the subject of our experience. If you accept that as a clear, though I admit not very philosophic way of putting what I conceive to be the actual facts of our experience, it seems quite simple. If messages are the only source of science, how comes it that those messages, if taken in their literal form, are entirely false ; that is to say, that the world which is revealed to the ordinary man in his ordinary moments (which we may call, I think, not inaccurately our intuitive view of the facts), is different from the naked system of messages, which if taken in their literal form are entirely misleading?

We all know that they are. It was not, I think, a fact known to our forefathers ; science had not sufficiently advanced in those days, but we all know perfectly well that what science now tells us about the situation, let us say, of matter, is in direct contradiction with the instinctive perceptions or experiences of the ordinary man. I do not think that that very familiar fact has been adequately taken account of by philosophers. It could not appear, of course, in the early days of philosophy, because the circumstances were not known. In the early days the philosopher and the man of science not only thought as 


\section{THE ANNUAL MEETING}

the ordinary man thinks in his ordinary moments about the material situation of the world; but they did not see any difficulty in it, or suppose that the facts were otherwise than the facts appeared. We now know that they are completely different.

It would be inappropriate at this stage to dwell upon a thing which is probably very familiar to all of you, but, merely for the sake of clearness, I will just mention one single fact. If there is a thing which all men in their ordinary moments conceive to be true of the material world, it is that it is solid, that it depends largely upon contact of one piece of matter with another, that there are continuous masses of matter, and so on. I am speaking of the ordinary world as we see it. "Solid facts "- "Seeing is believing "- that is the sort of thing you say and that is the sort of thing you believe. Of course, everybody I am addressing knows that the view of a solid world is eminently inconsistent-almost inconceivable-in view of the actual facts of the case.

Contact, so far as I am aware, the touching of one piece of matter by another piece of matter, never happens at all. So far as I comprehend the explanations given by the physicists, there is no such thing. Take a piece of matter so small that it eludes any direct powers of perception which we may possess ; take an ordinary atom-the ordinary chemical atom, dealt with and speculated upon by the chemist. It would be thought that if anything was solid in the world--solid in the ordinary familiar use of the term-it would be an atom, let us say, of gold. But we now know that, so far from being solid in the common sense of the term, the atom is made up of sub-atoms so far separated from each other that physicists, employing the best metaphor by which to explain its character to a student who is a stranger to these speculations, would have to say that an atom of gold consisted of sub-atoms as widely separated from each other as the members of the solar system are from each other and from the sun round which they revolve. I give that merely as an illustration-not as instructing you, because everybody here, no doubt, was fully aware of it before. My point is not the wonder, the strangeness, the almost illimitable strain which such conceptions put upon our powers of imagination. My point is quite different. It is this : how comes it that those messages on which all this knowledge of the atom of gold and the rest of it are entirely founded give us information involving a difference of character as great as that which separates the intuitions of the ordinary man about the ordinary affairs of life and the world in which it seems we all live? I do not think that facts like that can be explained by science alone. I think you must have a framework which is not material in which such a world as that can be conceived. If you ask me to develop that thought, I can only say that I have taken a good deal of trouble to develop it at length on various occasions, but that to-night it would be impossible for me to ask you so far to strain your attention as to listen to any development which at the present moment I could give to the theme. I gave a good deal of development to it the other day in a lecture which I delivered to the British Academy, and which appears, no doubt, in their proceedings, but which has not been published. Of course, I am not here to develop the argument beyond the point of showing that, if philosophy is to do for the individual what I think the individual wants, namely, if it is to enable him to see all his beliefs and ideas in a rational and synthetic whole, he must go beyond mere science in order to obtain any system which will satisfy discursive reason.

You will observe that I have come, by perhaps an unusual route, to one of the reasons why I think that this Society can do so much for its members. It is not that the doctrine which $I$ preach will be agreed to by all those to whom $I$ preach it ; it is that I think that they and myself can receive a great induce- 


\section{JOURNALOF PHILOSOPHICAL STUDIES}

ment to personal investigation of the highest type, from the attitude of mind which comes from a community of interests which a Society like this can encourage, however much we may differ upon the actual body of doctrine which we think the most rational possible for ourselves at this moment, in the place, in the year and with the opportunities which we have. I have no philosophy on this occasion to offer you, nor indeed on any occasion in the sense of having myself thought out problems which are easier to formulate than to solve, but I do feel that we all have a common interest in that kind of problem which I have laid before you and which I would have you know is in its character essentially a modern problem.

I do not mean to say that the sort of difficulties which I am talking about have not occurred before. Some of the philosophers have taken a good deal of trouble to devise a system of inductive philosophy-in other words, a theory of extracting from the messages, as I have called them, by which we all live, logical scientific conclusions. I do not think they have been very successful ; in fact, to put it quite plainly, I think they have so far completely failed, but I must say that, whether they have failed or succeeded, it is eminently worth our while to consider what lessons modern science has to teach us not merely about the world but about our way of discovering what the world is. That must change, and is changing before our eyes, by the growth of science.

I believe that this problem of messages requires a great deal more examination than it has yet received. I find it very hard to doubt that some of the lower animals-birds, for instance, in their migrations-must receive messages of a kind of which we have no idea, to which, probably, we are completely unsusceptible. But, whether we are unsusceptible or not, we at all events have not been able to isolate or to explain the factors involved in migration, as we isolate and explain so many of the messages we get from the stars or from each other or through what we call the five senses. That is a problem for science, and men of science have striven, and are striving, to solve it. I think they will admit that they have so far not succeeded, but what I want you to realize is that, if you are to appreciate the theory of messages, which I have explained-the theory of our personal sense experiences-and bring it into a really coherent whole, you will have to indulge in intellectual labours wholly alien to the labours of the chemist in his laboratory, of the physicist examining and experimenting with electro-magnetism, of the biologist, of the physiologist, or the psychologist dealing with the senses.

Thus it comes about that I should like the members of the Society in the first place to feel that their individual object is to form as rational a view of their own convictions as they can contrive, and, in the second place, to make it clear to all who listen to them how widely different and yet how intimately concerned are the labours of the philosopher on the one side and the labours of the man of science on the other. I believe that if this Society keeps those general principles in view, and each person in his own fashion deals with his own problems to the best of his ability, we shall perform a great and valuable function in the society into which we have been born. Ladies and gentlemen, I thank you. (Loud applause.)

The Right Hon. LoRd Hanworth, K.B.E. (The Master of the Rolls), proposed a vote of thanks to the Earl of Balfour. Mr. A. D. LindSAY, C.B.E., M.A. (Master of Balliol College, Oxford), Deputy Chairman of the Council, seconded the vote, and it was unanimously accorded.

The proceedings then terminated. 